\title{
СИНТЕЗ АДАМАНТИЛСОДЕРЖАЩИХ ИЗОСЕЛЕНОЦИАНАТОВ И 1,3-ДИЗАМЕЩЁННЫХ СЕЛЕНОМОЧЕВИН НА ИХ ОСНОВЕ
}

\section{Я.П. Кузнецов, Е.В. Самохвалова, В.В. Бурмистров, Е.В. Шишкин, Г.М. Бутов}

Волгоградский государственный технический университет, 400005, Россия, г. Волгоград, пр. Ленина, 28.

DOI: 10.19163/MedChemRussia2021-2021-386

E-mail:yroner@mail.ru

Двухстадийный методом синтезированы коммерчески малодоступные арил-и 2-адамантилизоселеноцианаты (схема 1).

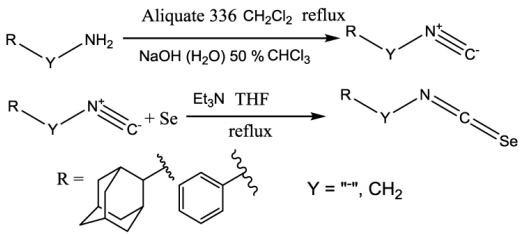

Схема 1.

Выделение изонитрилов связано с тем, что целевые изоселеноцианаты разлагаются до соответствующих аминов под действием щёлочи. На второй стадии изонитрил взаимодействовал с селеном в присутствии основания Льюиса. Выходы на стадии получения изонитрилов составили от 35 \% (в случае адамантилзамещённых) до 90 \% (в случае ароматических заместителей). Реакция взаимодействия селена с изонитрилом во всех случаях даёт практически количественный выход. Выделение продуктов проводили промывкой $1 \mathrm{H}$ раствором $\mathrm{HCl}$ и упариванием растворителя. Анализ реакционной массы и продуктов реакции проводили методом ГХ-МС. На основе полученных изоселеноцианатов была синтезирована серия 1,3-дизамещённых селеномочевин (схема 2).

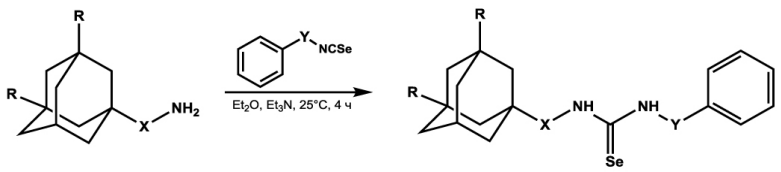

Схема 2.

$\mathrm{R}=\mathrm{H}, \mathrm{X}=\langle-\rangle, \mathrm{Y}=\langle-\rangle(1) ; \mathrm{R}=\mathrm{H}, \mathrm{X}=-\mathrm{CH}_{2}-\mathrm{Y}=\langle-\rangle(2) ; \mathrm{R}=\mathrm{H}, \mathrm{X}=-\left(\mathrm{CH}_{2}\right)_{2}-\mathrm{Y}=\langle-\rangle(3)$;

$\mathrm{R}=\mathrm{H}, \mathrm{X}=-\mathrm{CH}\left(\mathrm{CH}_{3}\right)-\mathrm{Y}=\langle-\rangle(4) ; \mathrm{R}=\mathrm{H}, \mathrm{X}=-\mathrm{C}_{6} \mathrm{H}_{4}-\mathrm{Y}=\langle-\rangle(5) ; \mathrm{R}=\mathrm{CH}_{3}, \mathrm{X}=\langle-» \mathrm{Y}=\langle-»(6)$;

$\mathrm{R}=\mathrm{H}, \mathrm{X}=$ «-», $\mathrm{Y}=-\mathrm{CH}_{2}-(7) ; \mathrm{R}=\mathrm{H}, \mathrm{X}=-\mathrm{CH}_{2}-\mathrm{Y}=-\mathrm{CH}_{2}-(8) ; \mathrm{R}=\mathrm{H}, \mathrm{X}=-\left(\mathrm{CH}_{2}\right)_{2}-\mathrm{Y}=-\mathrm{CH}_{2}-(9)$; $\mathrm{R}=\mathrm{H}, \mathrm{X}=-\mathrm{CH}\left(\mathrm{CH}_{3}\right)-\mathrm{Y}=-\mathrm{CH}_{2}-(10) ; \mathrm{R}=\mathrm{H}, \mathrm{X}=-\mathrm{C}_{6} \mathrm{H}_{4}-\mathrm{Y}=-\mathrm{CH}_{2}-(11) ; \mathrm{R}=\mathrm{CH}_{3}, \mathrm{X}=\ll-» \mathrm{Y}=-\mathrm{CH}_{2}-(12)$

Реакцию вели в сухом диэтиловом эфире при перемешивании в присутствии эквимолярного количества триэтиламина при комнатной температуре в течение 4-х часов с выходом 60-75\%. Полученные 1,3-дизамещённые селеномочевины, представляют интерес в качестве ингибиторов растворимой эпоксидгидролазы человека и млекопитающих (SEH).

Работа выполнена при финансовой поддержке Российского фонда фундаментальных исследований (грант № 20-03-00298). 